\title{
Ecologização na Agricultura Familiar, feiras e produtos artesanais na região Central do Rio Grande do Sul'
}

\author{
Everton Lazzaretti Picolotto \\ Cristina Bremm ${ }^{3}$
}

\section{Resumo}

A perspectiva de ecologização da produção na agricultura familiar vem ganhando importância nas últimas décadas. Por meio do resgate de práticas de produção artesanais e de conhecimentos tradicionais, ressignificados sob a ótica da ecologização, os produtos diferenciados oriundos da agricultura familiar têm adquirido espaço e conquistado consumidores. Este artigo procura refletir sobre o processo de transição para a agricultura agroecológica entre os agricultores familiares e assentados da região Central do RS e sobre as experiências das feiras coloniais e agroecológicas como espaços sociais onde ocorrem transações sociais de produtos e signos culturais entre produtores e consumidores. As feiras aparecem como espaços de realização dos produtores e dos produtos agroecológicos e coloniais. Nelas, os agricultores se realizam como sujeitos e são reconhecidos como tais pela comunidade, e os alimentos e produtos chegam ao seu destino final: a compra e o consumo consciente.

Palavras-chave: Agricultura familiar. Ecologização. Feiras. Região Central do RS.

\section{Introdução}

A ecologização da produção na agricultura familiar tem se tornado um tema importante nas últimas décadas. As organizaçóes de representação de agricultores e órgãos de assessoria técnica têm incluído em seus projetos de por vir e em suas açóes junto aos agricultores familiares a perspectiva de apoio

$1 \quad 0$ artigo é resultado do projeto "As organizações de agricultores no processo de ecologização na agricultura familiar no Centro do Rio Grande do Sul", desenvolvido junto ao Departamento de Ciências Sociais da Universidade Federal de Santa Maria (UFSM) entre 2013 e 2015. Para a sua realização, contamos com apoio decisivo do Fundo de Incentivo à Pesquisa - FIPE/UFSM e da Fundação de Amparo à Pesquisa do Estado do Rio Grande do SUl - FAPERGS, aos quais somos muito gratos.

2 Professor do Departamento de Ciências Sociais e dos Programas de Pós-Graduação em Ciências Sociais e em Extensão Rural da Universidade Federal de Santa Maria (UFSM).E-mail: everton.picolotto@ufsm.br

3 Mestranda junto ao Programa de Pós-Graduação em Ciências Sociais da Universidade Federal de Santa Maria (UFSM).E-mail: bremmcristina@gmail.com 
a formas e técnicas de produção mitigadoras de impactos ambientais, resgate de práticas de produção artesanais e de conhecimentos tradicionais, diversificação produtiva, práticas de agricultura de base ecológica, estratégias de diferenciação de seus produtos com apelo ecológico e cultural, entre outras.

Ao se tratar do tema da ecologizaçáo da agricultura familiar ou dos produtos diferenciados, como os produtos coloniais (caseiros, artesanais, da colônia), algumas das questóes que logo emergem dizem respeito às dificuldades de comercialização destes e a "elitização" de seu consumo, seja pela rápida suposição de que somente uma "elite" poderia pagar pelos mesmos, seja pelas dificuldades proeminentes dos produtores acessarem ou criarem canais de comercialização para produtos diferenciados, visto que eles necessitam de cuidados especiais, certificação da garantia de sua qualidade e canais próprios para chegar ao consumidor.

Algumas experiências de ecologização da agricultura familiar e de assentamentos de reforma agrária têm mostrado que é possível produzir e comercializar produtos com contornos ecológicos ou artesanais e (re)conectar laços com grupos de consumidores locais, das comunidades em que os agricultores pertencem e com os quais partilham identidades e valores. As experiências das feiras de produtos coloniais e agroecológicos da regiáo Central do Rio Grande do Sul são os casos escolhidos para reflexão.

O presente texto busca refletir sobre o processo de transição para a agricultura agroecológica entre os agricultores familiares e assentados da regiáo Central do RS e sobre as experiências das feiras coloniais e agroecológicas como espaços sociais onde ocorrem transaçóes sociais de produtos e signos culturais entre produtores e consumidores. As reflexôes aqui sistematizadas são resultados de análise documental, entrevistas com dirigentes de organizaçóes de representação rurais e com agricultores familiares ecologistas. Com relação a estes últimos, também se fez visitas nas suas propriedades.

\section{Agricultura familiar no Sul do Brasil: entre a modernidade e a tradição}

Compreende-se por modernidade o "estilo, costume de vida ou organização social que emergiram na Europa a partir do século XVII e que ulteriormente se tornaram mais ou menos mundiais em sua influência" (GIDDENS, 
1991, p. 11). A modernidade se expressa por seu caráter dramático e abrangente de descontinuidade em relação ao tradicional, mesmo que se operem continuidades e náo uma ruptura total entre ambos. As transformaçóes pelas quais é marcada estabeleceram novas formas de interconexão social, desestruturando formas tradicionais e podem ser observadas no ritmo de mudança extremo, especialmente em relação ao advento de novas tecnologias; no escopo da mudança, visto que as transformaçóes sociais influenciam boa parte do globo terrestre; e na natureza intrínseca das instituiçóes modernas, dado que algumas formaçóes sociais inexistiam anteriormente, a exemplo do sistema político do estado-nação.

O que caracteriza o dinamismo da modernidade são os mecanismos de desencaixe entre tempo e espaço e a apropriação reflexiva do conhecimento. A separação entre tempo e espaço gera o desencaixe dos sistemas sociais, o "deslocamento das relaçóes sociais de contextos locais de interação e sua reestruturação através de extensóes indefinidas de tempo-espaço" (GIDDENS, 1991, p. 24). Seja pela criação de fichas simbólicas, como o dinheiro, permitindo a agentes distintos e distantes realizar transaçôes e expandir os mercados capitalistas, seja pelo estabelecimento de sistemas peritos, "sistemas de excelência técnica ou competência profissional que organizam grandes áreas dos ambientes material e social em que vivemos hoje" (GIDDENS, 1991, p. 30), que removem as relaçóes sociais da esfera local.

Sáo os mecanismos de desencaixe (o dinheiro e os sistemas peritos) que permitem a apropriaçáo reflexiva do conhecimento, a análise racional sobre passado, presente e futuro na tentativa de minimizar riscos, e que expandem as relaçôes sociais para além de localidades e situaçóes específicas. Nesse contexto de modernização reflexiva, as tradiçóes não são meramente aniquiladas, elas passam a ocupar outro lugar. Elas podem adquirir o sentido de "museus vivos", com artefatos que se tornam "relíquias" ou serem apropriadas de forma racionalizada por grupos sociais e reinventadas, causando a aparência de continuidade, mas continuidade artificial, por se tratar de realocaçóes destas em novos contextos impostos por questóes atuais (GIDDENS, 1997).

As sociedades tradicionais, de outra parte, eram caracterizadas pela permanência da conexáo entre tempo, espaço e lugar para a organizaçáo da vida social e da produçáo, a reflexividade estando limitada à reinterpretaçáo e ao esclarecimento da tradição, que possuía um papel central, inseria as atividades 
e experiências na continuidade do passado e estruturava o presente e o futuro sobre práticas recorrentes. A existência de poucos meios de demarcação temporal e espacial para a percepção de mudanças expressivas explica a resistência às mudanças (GIDDENS, 1991). Em contraste, as sociedades modernas são caracterizadas pela ruptura com os preceitos pré-estabelecidos e por endossar as potencialidades particulares, assegurando identidades móveis, mutáveis e a apropriação de novas possibilidades de ação aos indivíduos.

No Brasil, quando se analisa o processo de modernização da agricultura à luz desses parâmetros, observa-se um conjunto de açôes coordenadas para destradicionalizar as sociedades rurais e as formas de produzir na agricultura (PALMEIRA, 1989; BRUM, 1988; MARTINE; GARCIA, 1987; SCHMITT, 2001). Esse conjunto de açóes foi conduzido pela açáo do Estado e de agentes privados que privilegiaram mudanças na base técnica da produção no campo, em ampla escala, voltadas centralmente para as lavouras de exportação. Em especial a partir do final dos anos 1960, o setor agrícola do país passou a absorver e assimilar grandes quantidades de crédito para a compra de insumos industriais e máquinas agrícolas para desenvolver o processo produtivo e tecnificar a produção com o propósito de integrá-la aos circuitos modernos de comercialização (PALMEIRA, 1989).Todavia, além de mecanizar e tecnificar a lavoura, o processo modificou as relaçóes sociais e de produção e a agricultura foi incluída nas redes internacionais de fluxos de capitais e de comercialização de commodities. Os agricultores e a produçáo foram integrados ao mercado e à racionalidade do lucro e a sua propriedade que era local de vivência e subsistência familiar tornou-se especializada na produção de poucas culturas e criações (especialmente soja, trigo, milho, suínos, leite, frangos e uva), como atesta Brum (1988, p. 122-123), sobre o Planalto Gaúcho:

Rompeu-se o ritmo lento do mundo rural marcado pela tradição. Aumentou a velocidade do sistema de produção, bem como dos contatos e das informações. A visão de mundo ampliou-se, abarcando não apenas o distrito ou o município, mas o Estado, o País e o plano internacional. [...] O ritmo da vida é marcado pela marcha do trator e da automotriz e pela alternância das safras (trigo e soja), com as respectivas épocas de plantio e colheita.

Essas mudanças, além de alterarem profundamente a sociabilidade das comunidades tradicionais, também colocaram os agricultores em contato com outros agentes, os submetem a novas relaçóes de poder e promovem mudanças 
no habitus - conjunto de disposiçóes sociais duráveis e transferíveis que orienta o modo de ver, analisar, desejar e pensar as situaçóes práticas da vida e do mundo da produção, conforme Bourdieu (2011). Estes assumi ramo crédito bancário, os serviços de assistência técnica, as relaçóes com comerciantes de máquinas, equipamentos e insumos industriais e as transaçóes com os mercados internacionais. Foram inseridos gradativamente nas relaçóes impessoais do mundo urbano-industrial. Com estas influências da modernização foram incorporadas novas disposiçóes sociais para a sociabilidade e para produzir e comercializar os produtos da agricultura. Os colonos $^{4}$ foram induzidos a se tornarem cada vez mais "agricultores profissionais", integrados aos mercados e com menor autonomia. Como afirma Wanderley (2009, p. 188) o agricultor "não é mais seu próprio mestre", passa a depender de serviços de assistência técnica, crédito e insumos externos.

A modernização mostrou a sua face mais perversa para os agricultores familiares do Sul do paísa partir do final da década de 1970, quando começaram a aparecer diversos impactos ambientais, tais como: poluição, erosão e envenenamento; a dependência em relação a insumos externos; a perda das variedades localmente adaptadas; o desgaste do conhecimento sobre o manejo da biodiversidade local; a crescente desvalorização das atividades e dos produtos destinados à subsistência das famílias agricultoras (SCHMITT, 2001; BRANDENBURG; LAMINE; DAROLT, 2013). Na esfera socioeconômica, ocorreram outros "efeitos perversos" da modernização, tais como: aumento da concentração da propriedade; elevação das disparidades de renda; crescimento acentuado do êxodo rural; aumento da taxa de exploraçáo da força de trabalho agrícola; crescimento da taxa de autoexploraçáo nas propriedades menores; piora da qualidade de vida dos trabalhadores do campo (MARTINE; GARCIA, 1987; PALMEIRA, 1989).

Foi neste contexto que surgiram as primeiras experiências de agricultores familiares, assentados e suas organizações em busca de práticas agrícolas ecológicas, que fazem apreciaçóes críticas da modernização e que visaram a resgatar formas de produzir tradicionais. O empenho pelo resgate de técnicas próprias de produzir anteriores à modernização evidencia a preocupação desses atores

4 Por colonos, entende-se os descendentes de imigrantes europeus (alemães, italianos, poloneses, entre outros) que se estabeleceram em pequenas propriedades em regiões de matas não apropriadas pelos grandes domínios rurais, formando colônias de exploração agropecuária diversificada e voltada à subsistência familiar (ROCHE, 1969). 
com as consequências socioeconômicas e ambientais ao mesmo tempo em que alimenta projetos de autonomia camponesa, de resistência à subordinação frente à indústria (ao sistema bancário e outros agentes) e nutre perspectivas de trilhar novos caminhos.

Da convergência da preocupação dos agricultores e suas organizaçóes de representação com o interesse de Organizaçôes Não Governamentais (ONGs) e setores progressistas da Igreja Católica e Luterana com a reinserção social e produtiva dos colonos é que se constroem as primeiras experiências de agricultura ecológica ou alternativa na regiāo Sul do Brasil (REDE TA/SUL, 1997; BRANDENBURG, 2002; PICOLOTTO; BRANDENBURG, 2015). Surgem como um contra movimento à modernização intensiva da agricultura, ou como um contraparadigma produtivo, pois esta foi percebida, neste momento, "como ineficaz do ponto de vista econômico, ultrapassada do ponto de vista técnico e tradicional do ponto de vista da organização social" (BRANDENBURG; LAMINE; DAROLT, 2013, p. 221).

Nessa perspectiva, as famílias agricultoras e os seus atores políticos, mesmo estando na contracorrente, buscam retomar práticas agrícolas tradicionais, de seu passado, características de uma maior autonomia produtiva, de menor dependência de crédito e de insumos externos. Ao resgatar práticas do passado, ressignificadas com questóes do tempo presente (preocupaçôes ambientais), os agricultores buscaram alcançar um novo espaço de reconhecimento (HONNETH, 2009) na sociedade atual para a agricultura familiar e pensar, a partir de sua "experiência" enquanto grupo social (THOMPSON, 1987), um novo modelo de agricultura com menores impactos no ambiente e formas de (re)conexáo com as comunidades locais. Para isso,repensar algumas técnicas de produçáo foi importante, mas foi por meio das organizaçóes coletivas que se tornou possível criar canais alternativos de comercializaçáo, sob controle próprio.

Essas experiências das décadas anteriores deram as bases para que, a partir dos anos de 1990, fossem abertos novos mercados para produtos elaborados de forma ecológica e tradicional. As formas de produção caseiras passaram a ser valorizadas e frequentemente compreendidas e associadas como mais saudáveis e naturais do que os produtos industriais, por um público consumidor que teve ou tem algum contato com o meio rural (LONGHI; SANTOS,2003; DORIGON; RENK, 2011). Sobre esses aspectos, é possível 
fazer uma relação da agricultura ecológica e a produção caseira de alimentos, praticadas pelos colonos, com a noção de "habilidade artesanal" (SENNETT, 2013), como prática criadora de artefatos "bem feitos" e também de cidadãos. Para Sennett (2013), a habilidade artesanal do bom artesão associa a sua perícia à comunidade. Ou seja, o bom artesão, o perito, assim como o bom agricultor ecologista e o que elabora os produtos coloniais, náo desenvolvem as capacidades essenciais básicas da perícia artesanal quando trabalham sozinhos ou se isolam dos círculos sociais de artífices e agricultores.

As competências de saber localizar um problema, questionar-se sobre ele e abrir um problema, ou "abrir-se para" a possibilidade de fazer as coisas de modo distinto são mais desenvolvidas quando há o estímulo ao trabalho em grupo e o contato frequente com quem está envolvido no mesmo projeto e na busca de soluçóes para os mesmos problemas. Apesar de todos os seres humanos serem dotados dessas "capacidades", elas não são desenvolvidas amplamente da mesma forma, assim como os conhecimentos adquiridos só podem ser renovados por meio de seu uso, no processo de socializaçáo, "sendo cada capacidade ativada ou reprimida pela cultura” (SENNETT, 2013, p. 308).

A crescente influência dos valores difundidos pelo movimento ambientalista sobre os cuidados ambientais e com a saúde (BRANDENBURG; LAMINE; DAROLT, 2013) aliado como contato prévio de alguns consumidores com o meio rural têm feito aumentar a preferência pela compra de produtos agroecológicos e coloniais e evidencia o desejo de valorizar algumas tradiçóes (de forma racionalizada e adequada com os valores atuais). Assim como o artesão, do latim "demioergoi" (demios = público ergos $=$ produtivo $)$ (SENNETT, 2013, p. 32), os agricultores familiares e assentados aperfeiçoam e aprimoram suas práticas, a produção e a comercializaçáo dos artefatos diferenciados que produzem em conjunto, envolvendo a família, a comunidade, o auxílio dos assistentes técnicos e as demandas dos consumidores. A presença comunitária nos resultados do trabalho contrapóem a individualização e fragmentação que caracteriza o processo produtivo moderno.

\section{Os atores sociais e as feirasnas experiências de ecologização no Centro do RS}

As organizaçóes de agricultores familiares e de assentados de reforma agrária com atuaçáo no estado do Rio Grande do Sul têm dialogado ou 
mesmo se aproximado de algumas pautas do movimento ambientalista. O Movimento dos Trabalhadores Rurais Sem Terra (MST), a Federação dos Trabalhadores na Agricultura Familiar da regiáo Sul (FETRAF-Sul), a Federação dos Trabalhadores na Agricultura do RS (FETAG), vinculada a Confederação dos Trabalhadores na Agricultura (CONTAG) e o Movimento dos Pequenos Agricultores (MPA) são atores de representação dos agricultores familiares e assentados de reforma agrária que mais claramente, desde a década de 1990, têm procurado incluir em seus programas políticos essas preocupaçóes (COSTA NETO; CANAVESI, 2002; CARVALHO; BRUSSI, 2004; PICOLOTTO; BRANDENBURG, 2015). Orientam, cada um a sua forma, ações práticas às organizações locais (sindicatos, associações, cooperativas) e agricultores de sua base social para a conversão de suas práticas produtivas para padróes de agricultura ecológica.

Por se tratarem de organizaçóes de representação de agricultores familiares, a sua vinculação com a pauta ambiental não é algo natural, mas foi construída pouco a pouco nas vivências dos "efeitos perversos" da modernização agrícola. A abertura de alguns canais de diálogo com o movimento ambientalista ocorreu em um contexto bem específico das décadas de 1980 e 1990. Foi no contexto de desgaste do modelo de produção agrícola considerado moderno (e retomada de práticas tradicionais e de autonomia), de construção de oposição às grandes obras realizadas em nome do desenvolvimento nacional (barragens, estradas etc.), de crise do regime militar, do processo de abertura política e redemocratização do país, de realização da II Conferência Mundial sobre Meio Ambiente e Desenvolvimento no Brasil (Eco-92), em 1992, no Rio de Janeiro, e da participaçáo de alguns movimentos brasileiros na Via Campesina (organização internacional de camponeses), que se propiciou a "oportunidade política" (TARROW, 2009) para que os movimentos sociais do campo também discutissem a situação da agricultura e a sua relação com o tema ambiental. Alguns laços foram estabelecidos com o movimento ambientalista, em especial com a expectativa de incorporar nos programas políticos dessas organizaçóes de agricultores a perspectiva de ecologizaçáo da agricultura (BRANDENBURG, 2002; ALONSO; COSTA; MACIEL, 2007; PICOLOTTO; PICCIN, 2008; VALADÁO; BANDENBURG, 2009).

Se, do ponto de vista acadêmico, a agroecologia é entendida como enfoque científico destinado a dar subsídios para a transiçáo dos atuais modelos 
de desenvolvimento rural e de agricultura convencionais para estilos de desenvolvimento rural e de agricultura sustentáveis (SEVILLA GUZMÁN, 2000; CAPORAL; AZEVEDO, 2011), para as organizaçóes de agricultores, os sentidos atribuídos a esta categoria normalmente são mais amplos e aplicados às suas próprias experiências e práticas de agricultura que rompem em alguma medida com os modelos convencionais. Segundo aponta Almeida (2003, p. 505): "a agroecologia substituiu, pouco a pouco, a noçáo-chave (e, reconhecidamente, um pouco fragmentada) de 'tecnologia alternativa" muito em voga na década de 1980. A noção de agroecologia veio a substituir outras que eram usadas com sentidos semelhantes pelos movimentos, mas veio também dar novos contornos para as experiências e os programas políticos destes atores. Passou a ser pensada não somente como uma intervençáo técnica localiza$\mathrm{da}$, mas a ter presente dimensóes sociais e culturais e estimular a formulação dos seus programas políticos de desenvolvimento rural (ALMEIDA, 2003; PICOLOTTO; BRANDENBURG, 2015).

Orientadas por esta perspectiva, nas duas últimas décadas, essas organizaçóes nacionais de representação da agricultura familiar construíram projetos de desenvolvimento rural em que assumem contornos ecológicos. Tais como: a CONTAG e a FETRAF construíram o Projeto Alternativo de Desenvolvimento Rural Sustentável e Solidário, como diretriz para transformar a agricultura familiar em modelo de exploração agropecuária sustentável no país, e nele a agroecologia assume um lugar central (a primeira versão deste projeto é de 1993). O MST e o MPA assumiram a construçáo da agroecologia como modelo de produçáo na agricultura e a tarefa de construir maior autonomia para os agricultores e assentados. O MPA tem formulado o que chama de Projeto Camponês, como conjunto de diretrizes e açóes para ecologizar a agricultura 5 .

As orientaçôes das organizaçóes nacionais são apropriadas pelas suas representantes locais de formas singulares na regiáo Central do RS. Se, de um lado, constatou-se que os Sindicatos dos Trabalhadores Rurais-STRs (vinculados à FETAG-RS) têm pouca relação com as experiências de ecologização na região, por outro, especialmente algumas cooperativas que mantém relaçôes com o sindicalismo e com os movimentos sociais têm atuado mais

5 Maiores detalhes sobre a trajetória e os projetos politicos e de agricultura destas organizações podem ser encontrados em Favareto (2006), Picolotto e Piccin (2008) e Picolotto e Brandenburg (2015). 
diretamente com esta perspectiva. Dentre estas estão: A) COOESPERANÇA - A Cooperativa Mista dos Pequenos Produtores Rurais e Urbanos da regiáo Central foicriada em 1989 por integrantes de projetos sociais da Arquidiocese de Santa Maria, chamado de Projeto Esperança. Dentre suas principais ações,está a construção de um "terminal de comercialização direta",em 1992, em local cedido pela Igreja (COLOMÉ, 2013; OLIVEIRA; ZANINI, 2014). Desde então, mantêm, neste espaço, o Feirão Colonial em Santa Maria. Não assume vínculo formal com organizaçóes sindicais, mas mantém laços de colaboração tanto com o sindicalismo da FETAG e da FETRAF, quanto com outros movimentos do campo, como o MST e MPA. B) COOPERCEDRO - A Cooperativa de Produção e Desenvolvimento Rural dos Agricultores Familiares é uma organização de agricultores de Santa Maria e regiáo, formada em 2006. Contou com apoio da prefeitura municipal em seus primeiros anos com vistas a implementar no município o acesso ao Programa de Aquisição de Alimentos (PAA) eao Programa Nacional de Alimentaçáo Escolar (PNAE). Essa cooperativa tem atuado centralmente na organizaçáo da produção (especialmente de hortigranjeiros), na assistência técnica e na viabilizaçáo de canais de comercialização para os agricultores familiares da região para esses mercados institucionais(CARVALHO, 2012). Contribuiu(junto com a COOESPERANÇA, um grupo de assentados do MST e a ASSINTRAF ${ }^{6}$ ) para formar uma feira agroecológica na Praça Saturnino de Brito em Santa Maria. Não tem relaçôes oficiais com as organizaçôes sindicais, mas mantém laços com uma rede de cooperativas da agricultura familiar que se relaciona com o sindicalismo da FETRAF e da FETAG. C) COOPERTERRA - A Cooperativa Regional da Reforma Agrária Mãe Terrafoi formada em 2001 por um grupo de agricultores assentados de reforma agrária dos municípios de Tupanciretã, Pinhal Grande, Jóia e Júlio de Castilhos. Mantém vínculos com o MSTe tem como objetivo a prestação de assistência técnica, com certa ênfase para a agroecologia, e viabilizar a comercialização da produção leiteira.Apoiou a iniciativa da formaçáo de uma Feira de Produtos Coloniais da Reforma Agrária existente desde 2002 em Tupanciretã (BARCELLOS, 2010).

6 A Associação Institucional dos Trabalhadores da Agricultura Familiar (ASSINTRAF) é um instrumento de atuação local da FETRAF onde esta não possui sindicato. Em alguns casos, as ASSINTRAFs, quando se fortalecem, são transformadas em Sindicatos de Trabalhadores na Agricultura Familiar (SINTRAs). A ASSINTRAF de Santa Maria passou por um período de fortalecimento no início dos anos 2000; entretanto, nos últimos anos, suas atividades têm declinado. 
Essas organizaçóes locais não atuam exclusivamente com produtos agroecológicos ou orgânicos, mas têm apropriaçóes particulares sobre a agroecologia e desenvolvem açóes para a ecologizaçáo da agricultura e para a criaçáo de canais locais de comercialização de produtos agroecológicos ou coloniais. Nessa perspectiva, o tema da diversificação da produção de alimentos pelas famílias agricultoras é visto como uma forma de ecologização - como já observou Barcellos (2010) - e, ao mesmo tempo,de aumentar o espaço de autonomia das famílias agricultoras, produzindo alimentos e preservando o meio ambiente. O relato de uma liderança do MST expóe esta associação da produção de alimentos com a perspectiva da ecologizaçáo, como uma perspectiva estratégica:

A gente está vendo que a alimentação no país está sendo uma das principais pautas hoje, que é a produção de alimentos. Hoje está em falta o alimento no mundo todo. Está custando caro às vezes pra familia os alimentos, e nós temos terras ociosas aí pra produzir e que estão plantando outros alimentos, que vai pra produção de ração pros bichos e não pra alimentação humana [...] o Movimento assumiu como uma bandeira isso. Pra produção ecológica, o orgânico demora mais. Mas, a ideia é a transição pro orgânico. Isso pra meIhorar a saúde das familias e a renda das familias mesmo... E principalmente pra família ter um produto mais saudável e vender o excedente. (Moacir $\left.{ }^{7}, \mathrm{MST}\right)$.

Ainda que esses temas mais gerais das preocupaçóes ambientais e da necessidade de produção de alimentos de forma saudável justifiquem a aproximaçáo dos movimentos (como o MST) com a agroecologia, outros agricultores da regiáo relataram que suas experiências familiares com envenenamento de indivíduos ou com dificuldades de obter renda para as famílias na produção convencional foram motivadores importantes para as suas iniciativas de transição para práticas de agricultura ecológica. Para alguns deles, especialmente os agricultores entrevistados de Santa Maria e municípios próximos (como Dona Francisca), a opção das feiras apareceu como um espaço importante para experienciarem novas formas de produção voltadas para a venda direta aos consumidores. Além dos que foram citados, em outros municípios,como Júlio de Castilhos, Sobradinho, Arroio do Tigre e Ibarama, as opçóes de comercialização dos produtos agroecológicos e coloniais são as vendas diretas na propriedade, de casa em casa para consumidores da comunidade ou das cidades próximas, os mercados institucionais (PAA, PNAE) e as vendas diretas para restaurantes.

7 Os nomes dos entrevistados foram substituidos por nomes fictícios para preservar as suas identidades. 
De toda forma, as feiras locais, além de serem um dos principais espaços de comercialização dos produtos agroecológicos e coloniais - como atesta a literatura: Dorigon e Renk (2011); Brandenburg, Lamine e Darolt (2013); Niederle (2014) -, também foram percebidas pelos agricultores de Santa Maria e municípios próximos como uma oportunidade para nova inserção produtiva, de geração de fontes de renda e de perceber e dar "valor" para os recursos e artefatos da propriedade, como é relatado por um agricultor:

Na metade dos anos 1990, quando nós começamos a fazer feira tudo que tinha na propriedade começou a ter valor. Antes ela tinha um valor de uso próprio. Assim, então, se tu tinha uma galinha ali, era pro consumo da casa; e, se não, não tinha [valor]. Depois que nós começamos a fazer feira, tudo teve um valor agregado ao econômico também, porque, se a galinha tá aí, vai pra cozinha. Mas, leva na feira também. Tenho ovos, tenho coisas. Tu já cria um pouco mais, leva pra feira, né. Tu tem. Planta umas mandioca, umas batata, e leva pra feira também. (Nestor, agricultor ecologista, COOESPERANCA).

A valorização dos produtos e dos agricultores não veio ao acaso na região Central do RS, foi uma construção intencional dos atores envolvidos. Uma concepção planejada e posta em prática no Projeto Esperança/COOESPERANÇA e outros atores. Após fracassos iniciais, pois os agricultores apenas produziam e entregavam os produtos para a cooperativa vender, deu-se a reflexão sobre os motivos da falta de êxito e foi decidido experimentar uma nova configuraçáo da relaçáo produtor-consumidor: a venda direta. Mesmo com dificuldades, habilidades sociais foram sendo desenvolvidas e novos laços foram estabelecidos com os consumidores urbanos:

No começo não foi muito fácil, por que o produtor dizia assim: "olha, eu sei produzir, mas não sei vender. Não é meu perfil vender". [...] nós argumentamos que seria importante fazer essa venda direta. O produtor, em primeiro lugar, ele dialogava com o consumidor. Segundo lugar, ele teria produtos de qualidade. E preço também. Terceiro lugar, ele ia pesquisando o que o consumidor mais queria. Que tipo de produto e qualidade e tudo. Então, esse contato direto, além de formar uma integração urbana e rural, era o caminho planejado. (Irmã Lourdes, coordenadora da COOESPERANÇA - COLOMÉ, 2013, p.73).

Atualmente, o Feirão Colonial possui certa consolidação, conta com quatro pavilhôes organizados segundo os tipos de produtos oferecidos: agroindústria, artesanato, hortifrutigranjeiros e área da alimentaçáo. A feira acontece às quartas-feiras no final da tarde e aos sábados pela manhá. 
Com base nas experiências iniciais do Feirão Colonial e de outras feiras similares de municípios da regiáo Sul (como Porto Alegre, Curitiba, Passo Fundo, Chapecó etc.),outras feiras foram organizadas na cidade e em outros municípios da região, como a Feira Agroecológica da Praça Saturnino de Brito, a Feira Colonial do bairro Camobi, a Feira dos Produtos Coloniais da Reforma Agrária de Tupanciretá, entre outras. A Feira Agroecológica da Praça Saturnino de Brito foi constituída com apoio da Prefeitura Municipal e contou com a participação de agricultores de organizaçóes diversas, dentre elas: da COOESPERANÇA, da COOPERCEDRO, da ASSINTRAF e de assentados de reforma agrária vinculados ao MST. Com a mudança de prefeito a partir de 2009 e alguns reveses das organizaçóes de agricultores participantes, atualmente essa feira está reduzida a dois grupos de famílias agricultoras que mantém atividades regulares na Praça nas terças-feiras pela manhã.

Ainda que a feira da Praça Saturnino de Brito tenha perdido força nos últimos anos, um dos agricultores ecologistas remanescentes observa que a opçáo por fazer feira, por escolher esse espaço como local privilegiado de transacionar seus produtos, tem se constituído em um estímulo para diversificar cada vez mais a sua produção:

Esse ano até quiabo plantei. Tem quiabo, tem a batata, tem feijão de vagem, tem rúcula, tem couve, tem espinafre, tem alface de 2, 3, 4 tipos, cebolinha, salsa, beterraba, couve, repolho, brócolis... Um pouquinho de tudo. Tem abóbora, feijão. Porque a feira, pra nós, não adianta nós ter uma carga de só um tipo de coisa. [...], porque, quando é bastante variedade, nós vendemos fácil. Agora, se nós enchesse tudo de alface, teria que ter contrato com algum mercado.(Iram, agricultor ecologista, COOPERTERRA).

A feira se tornou um incentivo adicional para investir mais e de um modo melhor na produção ecológica e na diversificação produtiva. De outra parte, os próprios entrevistados enfatizam que essa necessidade de oferecer certa variedade de alimentos na feira para manter os consumidores teria criado dificuldades para alguns agricultores garantirem a regularidade neste espaço, sendo um indício sobre o seu abandono da feira.

\section{A feira como espaço de realização de produtos e produtores}

A valorizaçáo social dos produtos e das práticas agrícolas as quais seguem padróes de produçáo que respeitam o meio ambiente acaba colocando em 
evidência possibilidades de relaçóes sociais de novos tipos entre agricultores e consumidores. Um dos artifícios que os consumidores podem fazer uso para ter maior segurança sobre as formas de produçáo e as origens dos alimentos são os selos de certificação que são expedidos para produtos orgânicos e agroecológicos e que são mantidos por empresas de certificação especializadas. $\mathrm{O}$ consumidor não tem acesso direto às características que definem o produto orgânico, ou seja, a ausência de determinados componentes químicos sintéticos (NIEDERLE, 2014). Portanto, o consumidor precisa confiar em intermediários técnicos que asseguram a qualidade do produto e dos processos de produção utilizados.

A constituição desses intermediários envolve a constituição de novos "sistemas peritos" (GIDDENS, 1991), com excelência técnica e competência profissional para sustentar as representaçóes instituídas em torno do consumo dos alimentos orgânicos. Esses sistemas compóem os fundamentos dos mecanismos de certificação, definindo as normas, os procedimentos e padróes daquilo que se convenciona como "produção orgânica" ou "agroecológica". Para definir a qualidade dos alimentos, esses sistemas transformam os atributos qualitativos em um conjunto homogêneo de medidas objetivas passíveis de codificação e mensuração. A qualidade passa a ser percebida como uma característica intrínseca ao bem (ou processo de produção) e é avaliada segundo critérios quantificáveis (nível de contaminação, volume, peso, produtividade, índice de matéria seca etc.) (NIEDERLE; ALMEIDA, 2013).

Esse processo de certificação operado por empresas especializadas ainda é uma realidade distante da grande maioria dos agricultores familiares por razôes de ordem técnica e pelo seu alto custo. Visando a criar instrumentos de certificaçáo autônomos, algumas organizaçóes de agricultores ecologistas têm desenvolvido outras formas de garantir a procedência segura dos seus produtos. O sistema participativo de garantia mostra-se, em muitas de suas características, antagônico ao modelo amparado em inspeção por terceiros (de fora). Nele, não há repartição entre verificados e verificadores e as garantias dão-se na forma de responsabilizaçáo coletiva e controle participativo por parte daqueles que estáo diretamente envolvidos e de atores sociais parceiros (agricultores, consumidores, mediadores). O exemplo mais conhecido de certificação participativa no Sul do Brasil é desenvolvido pela Rede Ecovida de Agroecologia (RADOMSKY, 2013; LUCION, 2016). 
Seguindo perspectivas semelhantes, em diversos municípios da região Sul do país têm emergido instrumentos de distinção dos produtos da produção familiar. Estes buscam diferenciar seus produtos e obter o reconhecimento de sua qualidade junto ao consumidor, seja por suas características de respeito ao ambiente e a saúde humana, como no caso dos produtos orgânicos e agroecológicos, seja por seus vínculos com a tradição e a cultura local, como no caso dos produtos coloniais.

Diversas organizaçóes de agricultores têm realizado trabalhos de resgate e (re)valorização dos produtos coloniais em toda regiáo Sul do país. Por "produtos coloniais", entende-se os produtos "tradicionalmente processados no estabelecimento agrícola pelos 'colonos' para o autoconsumo familiar" (DORIGON; RENK, 2011, p. 102), tais como derivados da carne suína (salames, morcilha, copa, queijo de porco), derivados do leite (queijo colonial, dentre outros), doces e geleias de frutas, conservas de hortaliças, massas e biscoitos, açúcar mascavo, sucos e vinho, dentre outros. Tais produtos podem ser diferenciados dos convencionais por serem elaborados de forma tradicional, de forma colonial (como as famílias de colonos faziam no passado). Com base nesses diferenciais, são vendidos e comprados como artefatos singulares, ligados ao imaginário e à identidade do grupo social.

Em Santa Maria e municípios próximos, esse trabalho de valorização dos produtos agroecológicos e coloniais está no centro da estratégia de viabilização de um canal alternativo de comercialização para os produtos da agricultura familiar. O Projeto Esperança/COOESPERANÇA mantém espaços de comercialização direta, onde os agricultores e artesãos (urbanos e rurais) disponibilizam seus produtos para os consumidores desde o início dos anos de 1990. O espaço mais consolidado é o Feirão Colonial, que acontece todas às quartas-feiras no final da tarde e aos sábados pela manhá no Centro de Referência de Economia Solidária Dom Ivo Lorscheiter, e todo ano neste mesmo espaço, no mês de julho,acontece por uma semana a Feira Internacional do Cooperativismo (FEICOOP) e a Feira Latino-Americana de Economia Solidária com a participaçáo da rede nacional e internacional do cooperativismo e da economia solidária. $\mathrm{O}$ projeto também mantém outras feiras uma semana por mês na Praça Saturnino de Brito e na Rua 24 Horas. O foco das feiras estános alimentos da agricultura familiar - apresentados como produtos coloniais e agroecológicos/orgânicos -, mas também são 
ofertados produtos artesanais em geral, mudas de plantas, livros (sobre agroecologia e economia solidária), entre outros.

O apelo à ligação com uma forma de fazer, um saber fazer, tradicional do grupo social dos colonos é percebido como um valor positivo. Em uma entrevista realizada com um produtor de doces de frutas (schimier ou chimia $^{8}$ ), fica evidente a diferenciação que é construída ao se comparar os produtos coloniais aos industrializados:

Se você pegar um pote de schimier das minhas coloniais e abrir, e abre um do mercado que é de uma agroindústria grande. Só no abrir, no cheiro, você vai notar. A gente trabalha com mais fruta... cozinha em quantidades pequena, dá mais sabor. Não tem, tem vários fatores. E não usa conservante, não usa produto químico nenhum. É só a fruta, açúcar, cozimento. E vai no pote, e deu. E no mercado não. Nas agroindústrias grandes, eles botam conservantes. Tem que conservar tanto tempo pra não perderem. Não tem gosto. Ele perde o gosto. (Gabriel, agricultor familiar participante da FEICOOP).

O depoimento ressalta as diferentes qualidades de cada produto e o potencial que os produtos da agricultura familiar podem ter desde que se diferenciem daqueles das grandes empresas. A forma de produzir da agricultura familiar difere tanto por seguir o modo ambientalmente correto quanto por resgatar positivamente elementos culturais do grupo social dos colonos. A valorizaçáo dos produtos elaborados de maneira artesanal evidencia uma das formas de dar valores positivos para a agricultura familiar, para suas raízes e seus alimentos típicos que encontram mercados locais e regionais em consumidores que, muitas vezes, têm ou tiveram alguma relação com o meio rural e também valorizam ou passam a dar valor a esses produtos.

A aquisiçáo de um queijo, de uma chimia ou um salame colonial é mais que a compra de um produto diferenciado: "trata-se de um ato cultural, repleto de representaçóes e significados, de uma volta ao passado, à infância, de valorização de um modo de vida e de resgate ao sentido de pertencimento àquela tradiçáo" (DORIGON; RENK, 2011, p. 109). Nesse sentido, se (re) constroem vínculos de pertencimento a certa cultura e também de valorização do saber fazer dos agricultores que passam a dar nova importância às formas artesanais de elaboração de determinados alimentos típicos.

8 Segundo o Dicionário Informal (2009), "Chimia é uma derivação da palaura alemã schimier, que significa doce pastoso ou geleia". 
Acompanhando o processo de revalorização dos produtos coloniais também as próprias famílias de agricultores promovem "atitudes positivas" (HONNETH, 2009) frente a hábitos, formas de produzir e produtos que estes sempre elaboraram para o seu autoconsumo, mas que nunca (ou quase nunca) tiveram um valor específico no mercado. No momento em que o salame ou o queijo colonial passam a ter um valor diferenciado no mercado, por serem elaborados por uma família de agricultores de forma artesanal, o agricultor, enquanto sujeito, igualmente passa a ser valorizado pelos consumidores e assume atitudes positivas frente a si próprio, à sua história e aos artefatos que elabora. Melhora a sua autoestima social ao se perceber reconhecido pelo outro.

Uma preocupação presente nas experiências de feiras diz respeito à construção da relação de confiança e de reconhecimento entre produtores e consumidores. Uma liderança da COOESPERANÇA entrevistada relata esta preocupação:

O consumidor é um zelador pela ecologia. É um papel muito importante que o consumidor tem. Ele olha no olho do produtor e questiona, questiona muito, precisa questionar. [...] O consumidor vai lá porque lá não é o mercado da multinacional, não é o mercado tradicional. Já vai lá porque é uma outra proposta. [...] A formação com a lealdade, a transparência, com a honestidade, com a agroecologia, com autogestão, com o consumo ético, como comércio justo, com preços também justos. Então, tudo que vem qualificar a vida. Nós temos o compromisso social e moral. (Irmã Lourdes, Coordenadora do Projeto Esperança/COOESPERANÇA).

Apesar de, na maioria dos casos, esses produtos náo possuírem qualquer tipo de certificação oficial (com exceção de dois agricultores do Feirão Colonial que possuem certificação da Rede Ecovida) que ateste suas características diferenciadas, os laços de confiança que envolvem produtores e consumidores são capazes de garantir os significados e valores diferenciados aos produtos. Analisar a qualidade dos produtos como um valor socialmente compartilhado permite acesso a uma nova possibilidade de leitura para compreender os processos de certificaçáo não convencionais. Alguns mercados carregam consigo "sinais distintivos" que apresentam aos consumidores diferentes formas de "enraizamento dos alimentos", tais como: "social (produto da reforma agrária), ecológico (produto orgânico), cultural (produto colonial), territorial (indicação geográfica) ou científico (ISO)” (NIEDERLE, 2014, p. 178). 
O fato de o produto não contar com uma certificação formal desse tipo não elimina suas qualidades diferenciadas: a qualidade pode ser identificada em valores construídos na comunidade local em relação direta entre produtores e consumidores, de modo que sinais distintivos institucionalizados, como os selos e as marcas, não são necessários para estabelecer relaçóes de confiança e de reciprocidade entre produtores e consumidores.

O consumo de produtos coloniais e orgânicos também pode estar associado a uma opção política de engajamento, de "consumo responsável" (PORTILHO, 2008), com causas ambientais, com a busca e o estímulo à produção de alimentos saudáveis ou mesmo de apoio aos agricultores familiares (um apoio financeiro visando a contribuir para mantê-los na atividade, produzindo alimentos saudáveis e de forma artesanal). Nesse sentido, segundo caracterizam Dorigon e Renk (2011, p. 105): “o produto colonial, quando consumido por urbano, pode constituir-se em elemento de resistência, uma recusa à padronização dos produtos industrializados”. Um ato intencional de valorizaçáo de determinada forma de produzir e dos agricultores que seguem padróes considerados adequados.

Os produtos orgânicos consumidos em feiras têm sido considerados como "bens de crença", pois a sua qualidade náo pode ser comprovada pelos consumidores, já que se baseiam muito mais na confiança, em um valor compartilhado, sendo essa uma alternativa para o consumidor escolher fortalecer os pequenos produtores locais. Adquirem assim uma conotaçáo de consumo como ato político, relacionado às escolhas alimentares e ao apoio a determinado formato de produção e comercialização, pois vai além da simples preocupação nutricional (PORTILHO; CASTAÑEDA, 2011).

Observa-se que as feiras se configuram em espaços sociais de trocas de produtos agroecológicos e coloniais, espaços de permuta de produtos artesanais da agricultura familiar. Conformam também espaços de sociabilidade entre produtores locais e regionais, consumidores, estudantes, onde são cultivadas relaçóes de amizade, confiança e troca de experiências e conhecimentos sobre o cultivo de determinada variedade agrícola ou a produçáo de algum alimento da agroindústria familiar. Nas palavras de um agricultor feirante:

À medida que a fila vai andando pra vender, o círculo vai aumentado. Vai sempre metendo mais um na roda. E assim vai crescendo. E eles vão ajudando a tu melhorar a qualidade 
do teu produto, porque aqueles cliente, consumidor de mais confiança, eles chegam e te dizem "Ah isso aqui podia ter um pouquinho mais de sal".[...] "Ah... porque que vocês não fazem essa mesma bolachinha aqui sem pintar?" [...] Só o fato de tu chegar lá e o pessoal "Ah", tem umas pessoas que passam assim", "Ah, como é que vocês estão? Bom dia, vim aqui só pra dar a mão pra vocês!". Não são cliente teu, mas "Bom dia!, como é que vocês tão lá fora?, "como é que tá não sei o quê?". Isso já te... Tu já tá pronto pro dia, né! Aí, já tá pronto pra pauleira que vier. Com essa, passa tudo. (Nelson, agricultor familiar do Feirão Colonial).

De acordo com Sennett (2013), o artesão ao desenvolver bem as técnicas de produzir coisas materiais também se aperfeiçoa nas interaçóes com os consumidores e com a comunidade, absorve as apreciaçóes sobre seus produtos e os melhora continuamente. A habilidade artesanal está baseada neste ato contínuo de aperfeiçoamento do artesão, dos artefatos que elabora e das suas relaçóes como membro de uma comunidade de relaçóes.

Com base no que se pode observar nas experiências aqui tratadas, pode-se afirmar que as feiras sáo o espaço de realizaçáo dos produtores e dos produtos agroecológicos e coloniais. É nelas que se completa o ciclo de produção dos alimentos da agricultura familiar, onde adquire sentido e se justifica todo o conhecimento teórico, as capacidades e o esforço produtivo empregado pelos agricultores no cultivo dos seus produtos. É para a finalidade da alimentação saudável por meio do respeito aos recursos ambientais e naturais que os alimentos são produzidos e essa finalidade só se completa na feira, no ato da compra e do consumo consciente. No ato de transacionar seus artefatos é que o agricultor se realiza como sujeito e é reconhecido enquanto tal pelos consumidores e demais membros desta comunidade simbólica formada nos círculos das feiras.

\section{Limites e as possibilidades da ecologização na agricultura familiar}

Ainda que as organizaçóes de representação de agricultores familiares e assentados de reforma agrária (MST, MPA, CONTAG e FETRAF) tenham projetos de agricultura que contém orientaçôes em direção à ecologização das práticas agrícolas, estas organizaçóes têm conseguido apenas estimular e apoiar algumas experiências de produção com contornos ecológicos nos contextos locais (como as tratadas neste artigo), onde normalmente predomina o 
modelo de produção convencional. Apostam que estas experiências bem sucedidas possam servir de modelo para serem difundidas amplamente. Mas, estas experiências de agricultura ecológica, de produçáo artesanal de alimentos e de canais diretos de comercializaçáo enfrentam uma série de dificuldades para serem bem sucedidas e tornar-se uma forma viável de produzir na agricultura, bem como, uma nova forma de realizar transaçóes de produtos alimentícios.

Dentre os principais limitantes identificados para a ampliaçáo da produção de alimentos orgânicos/agroecológicos e coloniais na regiáo está a ausência de mercados que tenham capacidade de absorver maiores quantidades destes produtos. Os principais espaços onde esses produtos são comercializados são as feiras, os mercados institucionais e a venda direta de casa em casa. Como tratado neste texto, são espaços importantes, mas ainda não adquiriram dimensóes maiores, capazes de competir com as grandes redes de supermercados. Atingem principalmente consumidores que já compóem a rede de relaçôes das famílias agricultoras e das feiras.

Outro ponto a ser levantado é a questáo das incertezas sobre o retorno dos investimentos na produção, pois, na percepção de uma parcela desses agricultores, a produçáo convencional traria retornos econômicos mais imediatos e seguros, o que faz com que a agroecologia ou mesmo a produção diversificada sejam vislumbradas como arriscadas, com maiores dificuldades. Além disso, os depoimentos ressalvam que o esvaziamento e o envelhecimento da população do meio rural contribuem para que as famílias apostem em atividades de menor necessidade de força de trabalho envolvida, como a soja, pois a diversificação de atividades e a produçáo agroecológica requerem maior aplicaçáo de trabalho. Ainda que muitas dessas famílias reconheçam que a policultura e a produçáo agroecológica sejam vantajosas do ponto de vista da preservaçáo dos recursos naturais, da saúde humana e de possibilitarem maior renda.

Ademais, outros fatores que limitam o desenvolvimento das práticas de agricultura ecológica são a dificuldade de assistência técnica e a descontinuidade do apoio das administraçóes públicas. O apoio dos governos é volúvel, pode deixar de existir com as mudanças de gestôes, como aconteceu com a feira agroecológica da Praça Saturnino de Brito, em Santa Maria, que deixou de ter o apoio da prefeitura em 2009, enfraquecendo a feira e limitando o espaço da comercialização de produtos agroecológicos na cidade. 
No que se refere à assistência técnica, alguns dos agricultores entrevistados recebem assistência da EMATER (Empresa de Assistência Técnica e Extensáo Rural do RS), mas esta náo está presente em todos os lugares da regiáo e nem consegue oferecer serviços para todos os agricultores. As organizaçóes cooperativas (como COOESPERANÇA, COOPERTERRA e COOPERCEDRO) e ONGs (como o CAPA - Centro de Apoio ao Pequeno Agricultor) vêm tendo um papel importante no apoio e assessoria do processo de ecologização da agricultura dos seus associados. A EMBRAPA (Empresa Brasileira de Pesquisa Agropecuária), em algumas propriedades do município de Ibarama, também oferece assistência técnica por estar realizando experimentos de novas culturas, como o cultivo de oliveiras de forma ecológica na propriedade de um agricultor entrevistado. Alguns agricultores também relatam que receberam incentivos de projetos da UFSM voltados a estimular a produção ecológica.

A dificuldade de assistência técnica se deve, em grande parte, ao fato de que as políticas de crédito condicionam a assinatura dos contratos à aplicaçáo das recomendaçóes tecnológicas "adequadas" para os cultivos almejados, o que na prática acaba sendo um entrave estrutural para a adoção de práticas agroecológicas, uma vez que as tecnologias reconhecidas pelos agentes financeiros são as convencionais. As tecnologias de produção agroecológicas, por serem de sistematização e desenvolvimento recente e com pouco interesse da parte das grandes empresas de insumos, por basearem-se, em alguns casos, em conhecimentos dos agricultores e apenas de forma complementar em conhecimentos científicos modernos, acabam tendo dificuldade de alcançar ampla disseminação e de serem reconhecidas pelos formuladores de políticas públicas e agentes financeiros.

As lideranças regionais ainda apontaram como um limitante para o desenvolvimento da produçáo agroecológica a falta de "conscientizaçáa" dos agricultores. Reconhecem a própria dificuldade que as organizaçóes têm para conscientizar e motivar os agricultores de sua base para a transiçáo para a agricultura ecológica. Neste sentido, deve-se observar também a dificuldade de promover rupturas no modelo de produção convencional, uma vez que o agricultor, ao longo do último meio século, assimilou o habitus (BOURDIEU, 2011) da modernização. Mudanças que visam alterar as disposiçóes sociais dos agricultores em suas formas de produzir e perceber os canais de mercado são muito onerosas e requerem grande envolvimento das organizaçóes comprometidas nesses projetos de ecologização da agricultura. 
De outra parte, deve-se ressaltar que a busca de ecologização da agricultura não pode ser preocupação somente dos agricultores e suas organizações, mas precisa ser compartilhada como Estado, os agentes econômicos e os consumidores. $\mathrm{Na}$ visão das lideranças entrevistadas, são necessárias mudanças de hábitos e na percepção sobre os produtos alimentícios disponibilizados. Os consumidores precisariam abrir mão das facilidades de aquisição de produtos industrializados nas grandes redes de supermercados e alterar sua forma de perceber o valor e o aspecto dos produtos, uma vez que os alimentos produzidos sem uso de agrotóxicos podem não ser os mais bonitos na sua apresentaçáo e normalmente têm menor capacidade de conservação nas prateleiras.

Diante dessas dificuldades de competir com os produtos convencionais, a busca pela criação e ampliação das feiras ecológicas e coloniais tem se constituído em uma das grandes preocupaçóes atuais dos agricultores e suas organizaçóes. Além de serem espaços de maior autonomia para os agricultores transacionarem seus produtos, eles percebem que nelas os seus produtos são bem aceitos e valorizados e eles próprios são reconhecidos como produtores preocupados com a saúde e o meio ambiente pela comunidade de relações das feiras.

\section{Considerações finais}

As experiências de ecologização na agricultura familiar na regiáo Central do Rio Grande do Sul mostram que os agentes sociais vivenciam de diferentes formas os processos de modernizaçáo da agricultura, sem desconsiderarem a preservação ou a recuperação de algumas tradiçôes para finalidades específicas. Nessa perspectiva, à medida que a modernidade é caracterizada pelo desencaixe dos sistemas sociais e a separação entre tempo e espaço com a introdução de fichas simbólicas (dinheiro) e de sistemas peritos de garantia e a influência da globalização sobre os acontecimentos locais (GIDDENS, 1991), as açóes dos agricultores se dão no sentido de resgatar conhecimentos e práticas agrícolas tradicionais, de seu passado, readaptando-os para a situaçáo presente com o objetivo de fomentar a produção ecológica e artesanal em contraposição à produçáo convencional intensiva (moderna). Nesse sentido, os agricultores buscam implementar boas práticas agrícolas que não degradem o ambiente e resultem em alimentos saudáveis para as suas famílias e os consumidores.

Importa observar que essa tentativa de resgatar ou preservar a tradiçáo envolve a organizaçáo do presente em relação ao passado com o objetivo de 
modelar o futuro. É uma forma de racionalizar elementos da tradição com objetivos atuais e do por vir, dar respostas para a questáo ambiental, gerar alternativas de renda, criar novos canais de mercado e restabelecer relaçóes com os consumidores. Assim, por meio da produçáo ecológica e colonial e da comercializaçáo direta em feiras, os agricultores da região Central do Rio Grande do Sul reforçam o objetivo de estabelecer relaçóes alimentares e de comércio baseadas na localidade e na proximidade com os consumidores, tentando "reencaixar" produçáo, comércio e consumo na esfera local.

Segundo essa ótica de reconstrução e ressignificação da tradição, buscou-se pensar as experiências dos agricultores de forma similar aos "artesãos" e "artífices" de Sennett (2013). À medida que se entende que ambos se caracterizam por buscarem realizar trabalhos bem feitos, aprimoram técnicas e conhecimentos construídos e apropriados das experiências individuais e dos grupos, das suas práticas de trabalho cotidianas, dos projetos realizados e problemas resolvidos em grupos de agricultores e artesáos, dos estudos e da atenção dada às sugestóes e às demandas dos consumidores em relaçáo aos produtos coloniais e ecológicos. De maneira similar ao bom artífice que não opta pelo isolamento, uma vez que se liga à comunidade, os agricultores e as lideranças das associaçóes e cooperativas pontuam a importância da comunidade de relaçóes estabelecida nas feiras no que diz respeito tanto ao aprimoramento e à troca de experiências para a produçáo quanto à venda dos produtos e ao reconhecimento que recebem enquanto sujeitos. Ademais, a revitalização dos laços comunitários entre produtores e consumidores contrapóem a individualização e a fragmentação que caracteriza o processo produtivo moderno.

\section{Referências}

ALMEIDA, J. A agroecologia entre o movimento social e a domesticação pelo mercado. Ensaios FEE, Porto Alegre, v. 24, n. 2, p. 499-520, 2003.

ALONSO, A; COSTA, V.; MACIEL, D. Identidade e estratégia na formação do movimento ambientalista brasileiro. Novos estudos CEBRAP, n. 79, p. 151-167, nov. 2007.

BARCELlOS, S. B. A formaçáo do discurso da agroecologia no MST. 2010. 139 f. Dissertação (Mestrado em Ciências Sociais do Desenvolvimento, Agricultura e Sociedade, no Programa de Pós-Graduação em Desenvolvimento, Agricultura e Sociedade, Universidade Federal Rural do Rio de Janeiro, Seropédica, 2010. 
BOURDIEU, P. Senso prático. 2. ed. Petrópolis: Vozes, 2011.

BRANDENBURG, A. Movimento agroecológico: trajetória, contradiçóes e perspectivas. Desenvolvimento e Meio Ambiente, n. 6, p. 11-28, jul./dez. 2002.

Os novos atores da reconstrução do ambiente rural no Brasil: o movimento ecológico na agricultura. Estudos Sociedade e Agricultura, v.19, n.1, 126-148, 2011.

.; LAMINE, C.; DAROLT, M. Institucionalização do movimento ecológico na agricultura: mercado e reorganização dos atores sociais. Estudos Sociedade e Agricultura, Rio de Janeiro, v. 21, n. 2, p. 221-247, 2013.

BRUM, A. Modernização da agricultura: trigo e soja. São Paulo: Vozes, 1988.

CAPORAL, F. R.; AZEVEDO, E. O.de (Org.). Princípios e perspectivas da agroecologia. Paraná: Instituto Federal de Educação, Ciência e Tecnologia do Paraná, 2011.

CARVAlHO, A. Possibilidades e limites do Programa Territórios da Cidadania a partir da sua realização no Território Regiáo Central e no município de Santa Maria/RS. 2012. 259 f. Dissertação (Mestrado em Geografia) - Programa de Pós-Graduação em Geografia e Geociências, Universidade Federal de Santa Maria, Santa Maria, 2012.

CARVALHO, H. J. A.; BRUSSI, A. J. E. Entre as pedras e as flores da terra. Lua Nova, n. 63 , p. $67-102,2004$.

COLOMÉ, F. Gramáticas do consumo: eticidade e engajamento político do Sul do Brasil. 2013. 161 f. Dissertação (Mestrado em Ciências Sociais) - Programa de Pós-Graduação em Ciências Sociais, Universidade Federal de Santa Maria, Santa Maria, Santa Maria, 2013.

COSTA NETO, C.; CANAVESI, F. Sustentabilidade em assentamentos rurais: o MST rumo à "reforma agrária agroecológica" no Brasil?. In: ALIMONDA, H. (Org.). Ecologia política: natureza, sociedad y utopia. México: Clacso, 2002. p. 203-215.

DICIONÁRIO INFORMAL. 2009. Disponível em: <http://www.dicionarioinformal.com. br/schimier>. Acesso em: 4 abr. 2014.

DORIGON, C.; RENK, A. Técnicas e Métodos Tradicionais de Processamento de Produtos Coloniais: de "miudezas de colonos pobres" aos mercados de qualidade diferenciada. Revista de Economia Agrícola, v. 58, n. 1, p. 101-113, 2011.

FAVARETO, A. Agricultores, trabalhadores: os trinta anos do novo sindicalismo rural no Brasil. Revista Brasileira de Ciências Sociais, v. 21, n. 62, p. 27-44, 2006.

GIDDENS, A. As consequências da modernidade. São Paulo: Editora UNESP, 1991. 
A vida em uma sociedade pós-tradicional. In: BECK, U.; GIDDENS, A.; LASH, S. Modernizaçáo Reflexiva. São Paulo: Editora da UNESP, 1997. p. 89-166.

HONNETH, A. Luta por reconhecimento: a gramática moral dos conflitos sociais. 2.ed. São Paulo: Editora 34, 2009.

LONGHI, A.; SANTOS, M. S. O CETAP e a biodiversidade. Passo Fundo: CETAP, 2003. LUCION, J. M. R. A gramática por trás do selo: agroecologia e processos de certificação participativos. 2016. 190 f. Dissertação (Mestrado em Ciências Sociais) - Programa de PósGraduação em Ciências Sociais, Universidade Federal de Santa Maria, Santa Maria, 2016.

MARTINE, G.; GARCIA, R. C. Impactos sociais da modernização da agrícola. São Paulo: Ed. Caetés, 1987.

NIEDERLE, P. A. Políticas de valor nos mercados alimentares: movimentos sociais econômicos e a reconstrução das trajetórias sociais dos alimentos agroecológicos. Século XXI- Revista de Ciências Sociais, v. 4, n.1, p. 162-189, jan./jun. 2014.

; ALMEIDA, L. A nova arquitetura dos mercados para produtos orgânicos: o debate da convencionalização. In: ; ALMEIDA, L.; VEZZANI, F. M. Agroecologia: práticas, mercados e políticas para uma nova agricultura. Curitiba: Kairós Ediçôes, 2013. p. 23-67.

OLIVEIRA, S. S.; ZANINI, M. C. C. Algumas considerações sobre a família camponesa: desafios e estratégias na reprodução social do campesinato no Feirão Colonial de Santa Maria/ RS. In:ENCONTRO ANUAL DA ANPOCS, 38., 2014, Caxambu. Anais... Caxambu: ANPOCS, 2014. p. 1-24.

PALMEIRA, M. Modernização, estado e questáo agrária. Estudos Avançados, [S. 1.], p. $87-108,1989$.

PICOLOTTO, E. L.; BRANDENBURG, A. Uma grande oportunidade: o sindicalismo e seus projetos de ecologização da agricultura familiar. Ambiente \& Sociedade, v. 18, n. 3, p. 1-18, jul./set. 2015.

; PICCIN, M B. Movimentos camponeses e questóes ambientais: positivaçáo da agricultura camponesa? Revista Extensáo Rural, v. 15, n. 16, p. 5-36, jul./dez. 2008.

PORTILHO, F. Consumidores de produtos orgânicos: discursos, práticas e auto-atribuição de responsabilidade ambiental. In: REUNIÃO BRASILEIRA DE ANTROPOLOGIA, 26, 2008, Porto Seguro.Anais... Porto Seguro: ABA, 2008. p. 1-17.

; CASTAÑEDA, M. Certificação e confiança face a face em feiras de produtos orgânicos. Revista de Economia Agrícola, São Paulo, v. 58, n. 1, p. 11-21, jan./jun. 2011. 
RADOMSKY, G. W. Certificaçóes, sistemas participativos de garantia e agricultura ecológica: aspectos da relação entre agricultores e consumidores. In: NIEDERLE P. A.; ALMEIDA, L.; VEZZANI, F. M. Agroecologia: práticas, mercados e políticas para uma nova agricultura. Curitiba: Kairós Edições, 2013. p. 297-326.

REDE TA/SUL. Interconectando ideias e ideais na construção da agricultura do futuro. In:ALMEIDA, J.; NAVARRO, Z. (Org.). Reconstruindo a agricultura: ideias e ideais na perspectiva do desenvolvimento sustentável. Porto Alegre: Ed. UFRGS, 1997. p. 169-185.

ROCHE, J. A colonização alemã e o Rio Grande do Sul. Porto Alegre: Globo, 1969.

SCHMITT, C. J. Tecendo as redes de uma nova agricultura: um estudo socioambiental da região serrana do Rio Grande do Sul. 2001. 395 f. Tese (Doutorado em Sociologia) Programa de Pós-Graduação em Sociologia, Universidade Federal do Rio Grande do Sul, Porto Alegre, 2001.

SENNETT, R. O artífice. 4. ed. Rio de Janeiro: Record, 2013.

SEVILLA GUZMÁN, E. Agroecología y desarrollo rural sustentable:una propuesta desde Latino América. In: CURSO INTENSIVO EM AGROECOLOGIA:PRINCÍPIOS Y TÉCNICAS ECOLÓGICAS APLICADAS A LA AGRICULTURA, 11, Rosario. Anais... Rosario, 2000. p. 1-29.

TARROW, S. O poder em movimento: movimentos sociais e confronto político. Petrópolis: Vozes, 2009.

THOMPSON, E. P. A formaçáo da classe operária inglesa: a árvore da liberdade. Rio de Janeiro: Paz e Terra, 1987. v. 1.

VALADÃO, A. da C.; BANDENBURG, A. A emergência da dimensão ecológica nos assentamentos rurais do RMST no Estado do Paraná. In: CONGRESSO BRASILEIRO DE SOCIOLOGIA, 14., 2009, Rio de Janeiro. Anais... Rio de Janeiro: SBS, 2009. p. 1-20.

WANDERLEY, M. N. B. O mundo rural como espaço de vida: reflexôes sobre a propriedade da terra, agricultura familiar e ruralidade. Porto Alegre: Ed. UFRGS, 2009.

Recebido em: 09/02/2016. Aceito em: 15/12/2016. 


\section{Greening in Family Agriculture, Fairs and Crafts in the Central Part of Rio Grande do Sul}

\section{Abstract}

Greening's perspective in family agriculture has gained importance in the past few decades. Through the recovery of artisanal producing practices and common knowledge, now seen in the optics of greening, the products from family agriculture have been gaining space and conquering consumers. This paper reflects on the process of transitioning to the agroecological agriculture between family farmers and settlers in the central region of RS and about the experiences found in colonial and agroecological fairs as social spaces where social transactions of products and signs have been taking places between consumers and producers. These fairs are being treated as spaces of realization of producers and products. In these fairs, farmers are treated as the main subjects and are recognized as such by their communities and the produced goods make their way to their final destination: conscious buying and consumption.

Keywords: Family agriculture. Greening. Fairs. Central part of RS. 